\title{
ANALISIS KUALITAS DAN PENGELOLAAN MATA AIR DI SEKITAR PEMBANGKIT LISTRIK TENAGA PANAS BUMI (PLTP) DESA SIKUNANG KECAMATAN KEJAJAR KABUPATEN WONOSOBO
}

\author{
Heri Setianto ${ }^{1}$, Tyahyo Nugroho Adji ${ }^{2}$, dan Andri Kurniawan ${ }^{3}$
}

Universitas PGRI, Palembang, Sumatera Selatan, Indonesia ${ }^{1}$, Fakultas Geografi, Universitas Gadjah Mada, Yogyakarta, Indonesia ${ }^{1,2,3}$ setianto.heri8@gmail.com

Diterima : Agustus ; Direvisi : Oktober ; Dipubikasikan: Maret 2016

\begin{abstract}
ABSTRAK Pemantauan kualitas air sangat penting untuk dilakukan karena mataair yang dikonsumsi masyarakat diduga telah mengalami pencemaran. Pencemaran diduga berasal dari Pembangkit Listrik Tenaga Panas Bumi yang berbatasan langsung dengan pemukiman penduduk yang mengandalkan mataair di sekitar pembangkit listrik. Tujuan dari penelitian ini adalah (1) Menganalisis kualitas mataair di Desa Sikunang, Kecamatan Kejajar, Kabupaten Wonosobo dengan adanya Pembangkit Listrik Tenaga Panas Bumi (2)Mengetahui pengelolaan pemanfaatan mataair yang ada di Desa Sikunang. Penelitian deskriptif digunakan untuk mendiskripsikan kualitas air dari mataair serta menggambarkan bentuk aktivitas pengelolaan air yang dilakukan oleh masyarakat. Metode yang digunakan dalam penelitian ini adalah metode survai. Sensus mataair dalam penelitian ini berjumlah 10 mataair. Penentuan responden dengan menggunakan Proporsional Random Sampling terhadap 70 masyarakat yang bertempat tinggal di Desa Sikunang. Wawancara mendalam melibatkan narasumber dengan sistem snowbolling, dengan mencari informan kunci. Hasil penelitian (1) Kualitas mataair di Desa Sikunang masih berada pada kondisi yang normal dilihat dari sifat fisika, dan kimia, sedangkan kualitas mataair berdasarkan kondisi biologis berada pada kondisi yang kurang baik karena berada dibawah ambang batas aman. Tidak terjadi pencemaran pada mataair yang disebabkan karena pengoperasian Pembangkit Listrik Tenaga Panas Bumi yang berada di Desa Sikunang. (2) Pengelolaan mataair di Desa Sikunang masih bersifat sangat sederhana dari segi sarana dan prasarana, kelembagaan, pembiayaan dan aspek peraturannya. Pengelolaan mataair di Desa Sikunang lebih mengedepankan fungsi sosial dari pada fungsi ekonomi dan lingkungan. Fungsi sosial yang dimaksud antaralain kerja sama, saling menghormati, gotong royong, kebersamaan, serta mengedepankan kepentingan bersama dalam pengelolaan mataair.
\end{abstract}

Kata kunci: daerah pembangkit listrik tenaga panas bumi; kualitas mataair; pengelolaan mataair.

ABSTRACT Monitoring of water quality is very important to do because springs are consumed by people suspected to have suffered contamination. Pollution probably derived from Geothermal Power Plant. Pollution probably derived from Geothermal Power Plant which is directly adjacent to residential areas that rely on springs around the power plant. The purposes of this study are (1) to analyze the quality of the springs in the village Sikunang, District Kejajar, Wonosobo regency with the Geothermal Power Plant, (2) Determine the management of the utilization of existing springs in the village Sikunang.Descriptive research is used to describe the quality of the water from the springs and describes the shape of the water management activities undertaken by the community. The method used in this research is the survey method. The sensus in this study amounted to 10 springs. Determination of respondents using Sampling Proporsional Random Sampling against 70 people who reside in the village Sikunang. Involving depth interviews with snowbolling system, by finding a key informant.Research result are (1) It is can be quality Sikunang springs in the village is still in normal conditions seen from the nature of physics, and chemistry, while the quality of the springs based on biological conditions that are in poor condition because it is under the safe threshold. Not pollution on the springs due to the operation of the Geothermal Power Plant located in the Village Sikunang. (2) Management Sikunang springs in the village are very modest in terms of infrastructure, institutional, financial and regulatory aspects. Management of springs in the village Sikunang emphasizes the social function of the springs from the economic and environmental functions. Management of springs in the village of Sikunang emphasizes the social function of the economic and environmental functions. Social function is cooperation, mutual respect, mutual cooperation, solidarity, and promote common interests in the management of springs.

Key words: the area of geothermal power plants; quality of the springs; the management of springs.

\section{PENDAHULUAN}

Masalah utama yang dihadapi oleh sumberdaya air meliputi kuantitas air yang sudah tidak mampu memenuhi kebutuhan yang terus meningkat dan kualitas air untuk keperluan domestik yang semakin menurun. Kegiatan Industri, kegiatan domestik, dan kegiatan lain dapat berdampak negatif terhadap sumberdaya air antara lain menyebabkan penurunan kualitas air. Kondisi ini dapat menimbulkan gangguan, kerusakan, dan bahaya bagi mahluk hidup yang bergantung pada sumberdaya air. Oleh karena itu 
diperlukan pengelolaan dan perlindungan sumberdaya air secara seksama (Effendi, 2003).

Pembangkit Listrik Tenaga Panas Bumi (PLTP) adalah industri yang bergerak dalam bidang pengadaan tegangan listrik. Kegiatan pengeboran panas bumi yang dimanfaatkan untuk pembangkit listrik berpotensi menimbulkan pencemaran lingkungan hidup terutama pencemaran terhadap air. Pencemaran berasal dari unsur garam yang terkandung pada sumber air panas serta zat kimia yang digunakan dalam sistem produksi pembangkit listrik. Kondisi ini tertuang dalam Peraturan Menteri Lingkungan Hidup No 08 Tahun 2009, menjelaskan bahwa kegiatan pembangkit listrik tenaga termal merupakan salah satu usaha kegiatan yang berpotensi menimbulkan pencemaran dan perusakan lingkungan hidup, oleh karena itu perlu dilakukan pengendalian terhadap pembuangan air limbah dari pembangkit listrik tenaga termal.

Salah satu Pembangkit Listrik Tenaga Panas Bumi (PLTP) di Indonesia terletak di Dataran Tinggi Dieng, Kabupaten Wonosobo, Jawa Tengah. Pembangkit Listrik didirikan dari hasil kerjasama antara PT. PLN dan Pertamina, dan secara managemen operasi dibawah tanggung jawab PT. Geodipa Energi yang didirikan pada tahun 2002 oleh PT. PLN dan Pertamina.

Kasus pencemaran air di Desa Sikunang berdasarkan berita harian surat kabar Pikiran Rakyat (Rabu, 01 Juli 2009), bermula ketika air dari mataair yang dikonsumsi masyarakat di Desa Sikunang berasa asin. Pemantauan kualitas air sangat penting untuk dilakukan karena masyarakat mengeluhkan konsumsi air di Desa Sikunang yang berasa asin, rasa asin dari air mataair yang dikonsumsi masyarakat diduga telah mengalami pencemaran. Pencemaran diduga berasal dari Pembangkit Listrik Tenaga Panas Bumi (PLTP) yang berbatasan langsung dengan pemukiman penduduk yang mengandalkan mataair disekitar pembangkit listrik. Kekhawatiran masyarakat terhadap kualitas air dikarenakan tidak ada sumber mataair bersih lain yang dapat dimanfaatkan selain mengkonsumsi air di daerah tersebut, oleh sebab itu pengkajian kualitas mataair penting untuk dilakukan sebagai upaya untuk mengetahui kualitas mataair.

Interaksi kehidupan masyarakat di Desa Sikunang dengan adanya Pembangkit Listrik Tenaga Panas Bumi (PLTP) adalah pemanfaatan mataair untuk memenuhi kebutuhan air domestik masyarakat. Mataair yang ada menjadi sumber utama pemenuhan kebutuhan air domestik masyarakat, daerah ini merupakan daerah lereng perbukitan yang tidak bisa dibuat sumur gali dan kondisi sungai yang berada di sisi jurang dengan kualitas air yang buruk sehingga mataair menjadi sangat penting di Desa Sikunang. Pemanfaatan mataair dilakukan dengan mengalirkan air melalui pipa-pipa menuju permukiman penduduk. Jarak mataair hingga ke rumah warga yang relatif jauh menyebabkan masyarakat harus menggunakan pipa air dengan biaya dan perawatan yang mahal. Analisis kualitas mataair di Desa Sikunang masih belum dikaji secara luas, oleh karena itu tujuan dari penelitian ini adalah (1) Menganalisis kualitas mataair di Desa Sikunang, Kecamatan Kejajar, Kabupaten Wonosobo dengan adanya Pembangkit Listrik Tenaga Panas Bumi (PLTP); (2) Mengetahui pengelolaan pemanfaatan mataair yang ada di Desa Sikunang, Kecamatan Kejajar, Kabupaten Wonosobo.

Daerah penelitian berada di Desa Sikunang, Kecamatan Kejajar, yang berada di wilayah administrasi Kabupaten Wonosobo, Provinsi Jawa Tengah. Secara astronomis lokasi penelitian berada pada koordinat $7^{0} 13^{\prime} 0^{\prime \prime} \mathrm{LU}-7^{0} 15^{\prime} 30^{\prime \prime} \mathrm{LS}$ dan $109^{\circ} 53^{\prime} 0^{\prime \prime}$ BT - $109^{\circ} 55^{\prime} 0 "$ BT dan berada pada ketinggian 1435$2.350 \mathrm{~m} \mathrm{dpl}$. Desa Sikunang memiliki luas wilayah 373,90 ha dengan rincian hutan negara seluas 227,90 ha, pekarangan seluas 9,24 ha, tegalan seluas 135,59 ha, dan 1,15 ha untuk peruntukan lainnya (BPS, 2014).

Kondisi geologi wilayah kajian secara genesis merupakan satu kesatuan dari kawasan Gunungapi Dieng. Pegunungan Dieng didominasi oleh batuan Gunungapi Dieng, selain itu terdiri dari batuan Gunungapi Jembangan, dan batuan Aluvial dan endapan danau.Daerah Pegunungan Dieng ditutupi oleh endapan berumur kuarter yang berupa aliran lava, material piroklastik, endapan freatik, endapan lahar, endapan permukaan, dan hasil endapan Sindoro (Sukyar, 1986). Jenis batuan yang terdapat di Pegunungan Dieng terdiri dari 10 unit batuan yaitu lava andesit Prau, lava andesit Nagasari, lava andesit Bisma, lava andesit Pagerkandang, lava andesit Merdada-Pangonan, lava andesit Kendil, lava andesit Pakuwaja, lava andesit Seroja, endapan alluvialkoluvial dan satuan teralterasi.

Hidrologi daerah penelitian umumnya mempunyai aliran sungai tipe radial (melingkar) yang berasal dari aliran di daerah bagian selatan yang lebih tinggi menuju daerah yang lebih rendah di sebelah utara Aliran sungai di daerah penelitian dipengaruhi oleh perbedaan ketinggian tempat dan gravitasi. Sumber air bersih masyarakat di Desa Sikunang adalah dengan memanfaatkan mataair untuk kebutuhan air domestik dan air sungai untuk kegiatan pertanian.

\section{METODE PENELITIAN}

Penelitian ini merupakan penelitian deskriptif, yaitu bertujuan untuk mendiskripsikan kualitas air 
dari mataair yang terdapat di Desa Sikunang serta menggambarkan bentuk aktivitas pengelolaan air yang dilakukan oleh masyarakat. Metode yang digunakan dalam penelitian ini adalah metode survai. Penelitian ini dilakukan di Desa Sikunang Kecamatan Kejajar Kabupaten Wonosobo yang merupakan daerah yang terletak di Pegunungan Dieng. Desa Sikunang merupakan desa yang berada di daerah Pembangkit Listrik Tenaga Panas Bumi (PLTP).

Data yang digunakan dalam penelitian ini terdiri dari data primer dan data sekunder. Data primer antara lain berupa pengukuran kondisi fisik, kimia, dan biologi air, analisis dilaboratorium serta angket di daerah penelitian. Data sekunder diperoleh dari berbagai sumber seperti studi pustaka, penelitian terdahulu, jurnal, laporan, dan dokumen-dokumen yang mendukung dari topik penelitian yang dikaji

Sampling dari penelitian ini terdiri dari tiga teknik sampling, pertama untuk menganalisis kualitas mataair adalah dengan menggunakan Sensus yaitu dengan menjadikan seluruh mataair yang ada di Desa Sikunang sebagai penelitian. Jumlah mataaair yang dijadikan sampel dalam penelitian ini berjumlah 10 mataair.

Kedua untuk penentuan kuesioner pada responden dengan menggunakan Proporsional Random Samplingterhadap masyarakat yang bertempat tinggal di Desa Sikunang untuk menggali informasi mengenai kualitas dan pengelolaan mataair yang berada di sekitarPLTP. Penekanan metode penelitian ini adalah pada karakter anggota sampel dengan pertimbangan mendalam diyakini oleh peneliti akan benar-benar mewakili karakter populasi. Responden yang digunakan dalam penelitian ini sebanyak 70 responden yang merupakan penduduk Desa Sikunang yang memanfaatkan mataair. Ketiga, penentuan informan kunci untuk wawancara mendalam melibatkan berberapa narasumber dengan tekniksnowbolling, dengan mencari informan kunci sebagai pihak yang akan diwawancarai. Jumlah sampel untuk wawancara mendalam yaitu 5 responden yaitu 2 responden perwakilan dari perangkat desa, 1 responden dari organisasi masyarakat yang mengelola mataair, 1 penduduk Desa Sikunang, dan 1 tokoh kunci masyarakat yang berpengaruh.

\section{HASIL DAN PEMBAHASAN}

Hasil pengamatan dan pengukuran parameter fisika (bau, warna, rasa,suhu, dan zat padat tersuspensi/TSS) pada mataair di Desa Sikunang disajikan dalam Tabel 1. Hasil pengukuran suhu menunjukan bahwa sampel mataair yang memiliki suhu terendah yaitu pada titik sampel ke- 4 yaitu Mataair Jurug Tengah (0378461 mT dan $9200560 \mathrm{mU}$ ) dengan suhu $10^{\circ} \mathrm{C}$, mataair Jurug Tengah terletak pada ketinggian $2078 \mathrm{~m}$ dpl. Lokasi Mataair Jurug Tengah masih terletak di daerah yang memiliki vegetasi penutup lahan yang lebih baik dibandingkan dengan lokasi titik sampel lain yang sebagian besar terdapat pada daerah pertanian. Suhu tertinggi mataair terdapat pada titik sampel ke- 8 dan ke- 10 yaitu Mataair Lik-lik (0377763mT dan $9201361 \mathrm{mU}$ ) dan Mataair Sidandang (0377297 mT dan $9200995 \mathrm{mU}$ ) dengan suhu masing-masing sebesar 19 ${ }^{\circ} \mathrm{C}$. Berdasarkan hasil pengamatan dan pengukuran di lapangan dari 10 mataair dan satu sampel air limbah terdapat satu mataair yang berwarna agak keruh yaitu Mataair Lik-lik dan untuk 9 sampel mataair yang lain menunjukan kondisi yang tidak berwarna.

Berdasarkan hasil pengamatan di lapangan dari sampel air pada mataair di Desa Sikunang ada dua sampel air yang memiliki bau belerang terletak pada sampel Mataair Lik-lik dan Mataair Senila kandungan bau pada air dipengaruhi oleh letak mataair yang terletak di daerah panas bumi. Selain Mataair Lik-lik dan Mataair Senila, sampel lain yang memiliki bau adalah sampel pada air limbah yang memiliki bau belerang yang sangat menyengat. Mataair yang memiliki konsentrasi TSS tertinggi yaitu pada Mataair Lik-lik yang terdapat di Dukuh Ngandam dengan konsentrasi $11 \mathrm{mg} / \mathrm{l}$, tingginya kadar terukur disebabkan karena partikel-partikel yang ukuran maupun beratnya lebih kecil daripada sedimen. Dengan parameter TSS pada mataair yang terletak dibawah $50 \mathrm{mg} / \mathrm{l}$ hal ini menunjukkan bahwa mataair yang terdapat di Desa Sikunang masih sangat baik dan layak dikonsumsi berdasarkan kandungan zat padatan tersuspensinya.

Hasil uji laboratorium terhadap parameter kimia mataair pada lokasi penelitian di Desa Sikunang disajikan dalam Tabel 2. Hasil uji laboratorium mengenai sifat mikrobiologi dengan parameter Bakteri Coliform total pada 10 sampel mataair di Desa Sikunang dapat dilihat pada Tabel 3.

Dari hasil uji laboratorium terhadap 10 sampel mataair di Desa Sikunang kandungan Bakteri Coliform pada mataair berkisar antara kurang dari 1,8 - lebih dari $1600 \mathrm{Mpn} / 100 \mathrm{ml}$. Dari 10 mataair dapat disimpulkan bahwa semua mataair mengandung Bakteri Coliform yang melebihi ambang batas berdasarkan baku mutu yang telah ditetapkan. Besarnya jumlah bakteri coliform disebabkan di daerah lokasi mataair merupakan pertanian kentang yang memanfaatkan pupuk organik, pupuk organik terserap kedalam tanah dan mencemari airtanah. Peta kualitas mataair di Desa Sikunang disajikan dalam Gambar 1. 
Berdasarkan hasil pengamatan, kuesioner dan wawancara mendalam yang dilakukan pada masyarakat dan tokoh kunci di Desa Sikunang, Kecamatan Kejajar, Kabupaten Wonosobo mengenai pengelolaan mataair diketahui bahwa sistem pengelolaan air bersih untuk kebutuhan air domestik masyarakat masih menerapkan sistem pengelolaan yang sederhana. Pengelolaan air bersih tertuang dalam Peraturan Pemerintah Nomor
16 Tahun 2005 yang menyatakan bahwa dalam pengelolaan penyediaan air bersih meliputi 5 subsistem yang saling mendukung untuk mencapai tujuan pengelolaan yang baik. Subsistem tersebut antara lain, aspek teknik operasional, aspek kelembagaan, aspek pembiayaan, aspek peraturan, dan aspek peran serta masyarakat.

Tabel 1. Kondisi Mataair di Desa Sikunang Berdasarkan Parameter Fisika

\begin{tabular}{clccccc}
\hline \multirow{2}{*}{ No } & \multirow{2}{*}{ Mataair } & Warna & Parameter Fisika & & \\
& & Tidak & Rasa & Suhu $\left({ }^{\circ} \mathrm{C}\right)$ & TSS $(\mathrm{mg} / \mathrm{l})$ \\
\hline 1 & Bengkok & Tidak & Tidak & Tidak & 16 & 6 \\
2 & Jurug Kulon 1 & Tidak & Tidak & Tidak & 16 & 3 \\
3 & Jurug Kulon 2 & Tidak & Tidak & Tidak & 16 & 10 \\
4 & Jurug Tengah & Tidak & Tidak & Tidak & 17 & 5 \\
5 & Sigogor & Tidak & Tidak & Tidak & 14 & 3 \\
6 & Lempong & Tidak & Berbau Belerang & Tidak & 14 & 2 \\
7 & Tlaga Sat & Berwarna Keruh & Berbau Belerang & Tidak & 18 & 3 \\
8 & Lik-Lik & Tidak & Tidak & Tidak & 17 & 11 \\
9 & Senila & Tidak & Tidak & Tidak & 19 & 3 \\
10 & Sidandang & & & 3 \\
\hline
\end{tabular}

Sumber: Analisis Data Primer (2014)

Tabel 2. Kondisi Mataair di Desa Sikunang Berdasarkan Parameter Kimia

\begin{tabular}{|c|c|c|c|c|c|c|c|c|}
\hline \multirow{2}{*}{ No } & \multirow{2}{*}{ Mataair } & \multicolumn{7}{|c|}{ Parameter Kimia (mg/l) } \\
\hline & & $\mathrm{pH}$ & $\mathrm{NO} 2$ & NO3 & Cr Tot & $\mathrm{Fe}$ & $\mathrm{Cu}$ & $\mathrm{Zn}$ \\
\hline 1 & Bengkok & 7,3 & 0,0019 & 92,02 & $<0,213$ & $<0,0208$ & $<0,0069$ & $<0,0022$ \\
\hline 2 & Jurug Kulon 1 & 7,7 & 0,167 & 63,57 & $<0,213$ & $<0,0208$ & $<0,0069$ & 0,0036 \\
\hline 3 & Jurug Kulon 2 & 6,5 & 0,167 & 63,57 & $<0,022$ & 0,076 & $<0,006$ & 0,004 \\
\hline 4 & Jurug Tengah & 7,6 & $<0,0013$ & 97,36 & $<0,213$ & $<0,0208$ & $<0,0069$ & $<0,0022$ \\
\hline 5 & Sigogor & 6,1 & 0,0044 & 69,46 & $<0,213$ & $<0,0208$ & $<0,0069$ & 0,0072 \\
\hline \multirow[t]{3}{*}{6} & Lempong & 5,6 & $<0,0013$ & 62,2 & $<0,213$ & $<0,0208$ & $<0,0069$ & 0,0619 \\
\hline & Baku Mutu & $6-9$ & 3 & 50 & 0,005 & 0,3 & 2 & 3 \\
\hline & NoMataair & \multicolumn{7}{|c|}{ Parameter Kimia } \\
\hline 7 & Tlaga Sat & 5,9 & $<0,0013$ & 38,66 & $<0,213$ & $<0,0208$ & $<0,0069$ & $<0,0022$ \\
\hline 8 & Lik-Lik & 6,2 & 0,0093 & 3,84 & $<0,213$ & $<0,0208$ & $<0,0069$ & 0,0056 \\
\hline 9 & Senila & 6,2 & 0,0046 & 47,65 & $<0,213$ & $<0,0208$ & 0,0346 & 0,0346 \\
\hline 10 & Sidandang & 5,9 & $<0,0013$ & 24,13 & $<0,020$ & $<0,0208$ & 0,0056 & 0,0056 \\
\hline & Baku Mutu & $6-9$ & 3 & 50 & 0,005 & 0,3 & 2 & 3 \\
\hline
\end{tabular}

Sumber: Analisis Data Primer (2014)

Tabel 3. Bakteri Coliform Total pada Mataair di Desa Sikunang

\begin{tabular}{clcc}
\hline No & Mataiir & Coliform $($ MPN/100 gr) & Baku Mutu MPN/100 gr \\
\hline 1 & Bengkok & 1600 & 0 \\
2 & Jurug Kulon 1 & 240 & 0 \\
3 & Jurug Kulon 2 & $>1600$ & 0 \\
4 & Jurug Tengah & 1600 & 0 \\
5 & Sigogor & $<1,8$ & 0 \\
6 & Lempong & $<1,8$ & 0 \\
7 & Tlaga Sat & $>1600$ & 0 \\
8 & Lik-lik & 94 & 0 \\
9 & Senila & 140 & 0 \\
10 & Sidandang & 23 & 0 \\
\hline
\end{tabular}

Sumber: Analisis Data Primer (2014) 


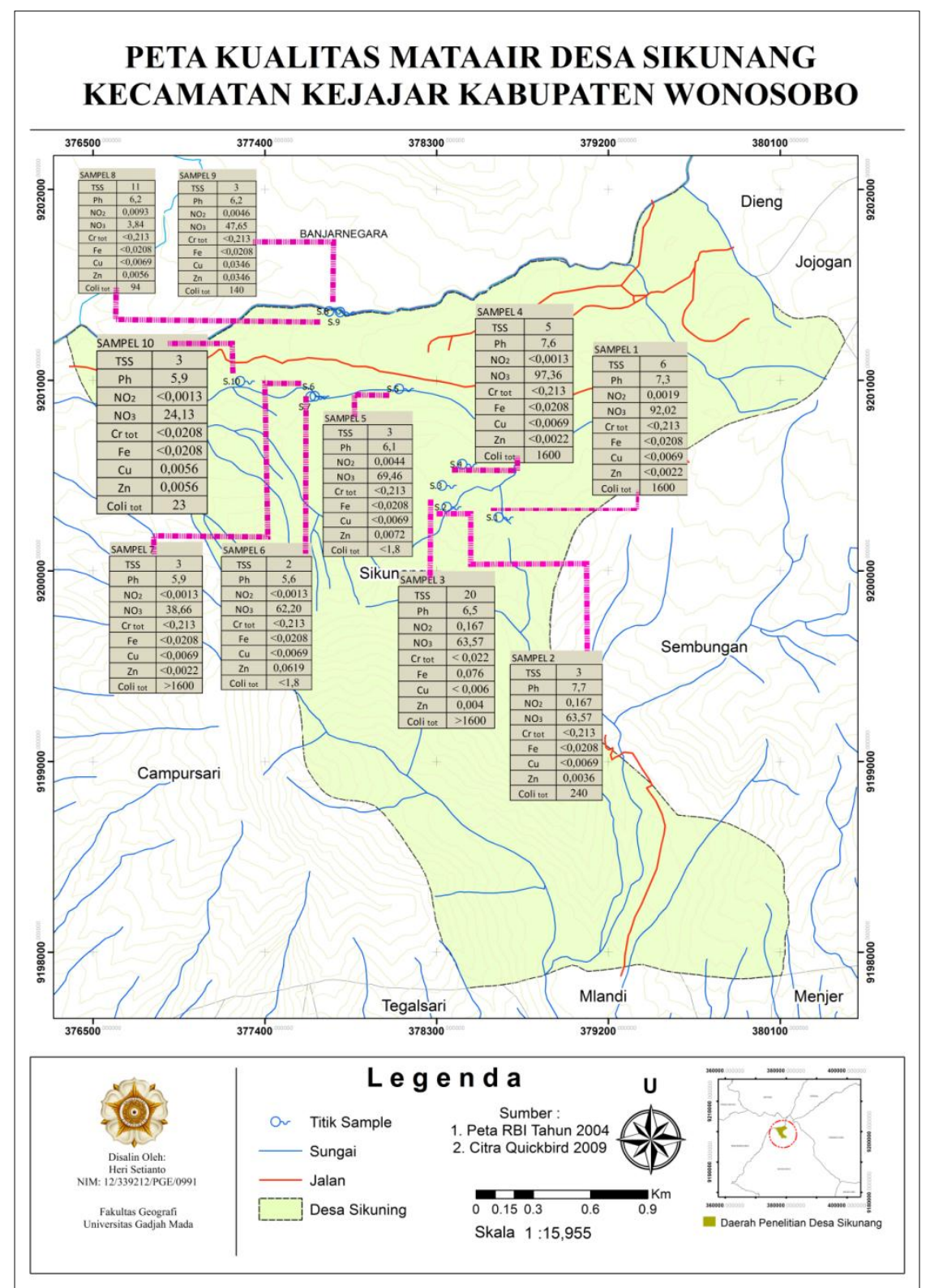

Gambar 1. Peta Kualitas Mataair

Aspek teknik operasional terkait dengan kualitas mataair meliputi kualitas dari sifat fisika, kimia dan biologis, sarana dan prasarana dalam distribusi, pemeliharaan dan operasional. Hasil penelitian yang telah dilakukan mengenai kualitas mataair di Desa Sikunang berdasarkan sifat fisika, sifat kimia, dan sifat biologisnya dapat disimpulkan bahwa kualitas mataair di Desa Sikunang masih baik untuk digunakan sebagai sumber kebutuhan air domestik masyarakat. Asumsi lain bahwa tidak pernah terjadi kasus penyakit yang diakibatkan karena masyarakat mengkonsumsi air dari sumber mataair yang ada di Desa Sikunang.

Jaringan distribusi air merupakan bagian dari upaya mendekatkan air dari sumber air ke tingkat kebutuhan hidup masyarakat di pemukiman. Distribusi air dari sumber mataair di Desa Sikunang menggunakan bangunan fisik yang berfungsi sebagai penampung dan pembagi. Bangunan penampung air dibagi menjadi tiga yaitu bak pembagi utama, bak pembagi desa, dan bak berjalan. Proses pendistribusian air di Desa Sikunang disajikan dalam Gambar 2.

Bak pembagi utama berupa bangunan tertutup dengan bagian dalamnya berupa sekat bangunan yang dipisahkan menjadi bak berdasarkan fungsi pembagiannya. Bak pembagi desa merupakan bangunan fisik yang digunakan untuk membagin air setelah air didistribusikan menggunakan pipa dan sampai ke desa, fungsi dari bak pembagi desa adalah untuk distribusi air ke dukuh atau kelompok rumah warga. Sedangkan bak berjalan merupakan bak terbuka yang berukuran lebih kecil yang berfungsi untuk membagi air ke rumah warga. Bentuk bak pembagi desa dan bak berjalan disajikan dalam Gambar 3.

Distribusi air dari mataair yangada di Desa Sikunang dilakukan menggunakan pipa plastik atau paralon dengan berbagai ukuran berdasarkan http://jurnal.ugm.ac.id/mgi | 33 
fungsinya. Sistem distribusi air bias dilakukan dengan merata serta mempermudah dalam pemeliharaan ataupun perbaikannya dengan pengawasan langsung yang dilakukan oleh warga melalui petugas yang telah ditunjuk (ulu-ulu) baik tingkat RT, dukuh, dan desa. Tugas dari ulu-ulu adalah melakukan pengawasan terhadap sarana dan prasarana distribusi air serta melakukan pengawasan dalam pembagian volume air pada setiap bak berjalan yang didistribusikan langsung ke masyarakat agar tidak ada permasalahan dalam pembagian volume air. Alur distribusi air dari mataair untuk sampai ke rumah warga disajikan dalam Gambar 4.

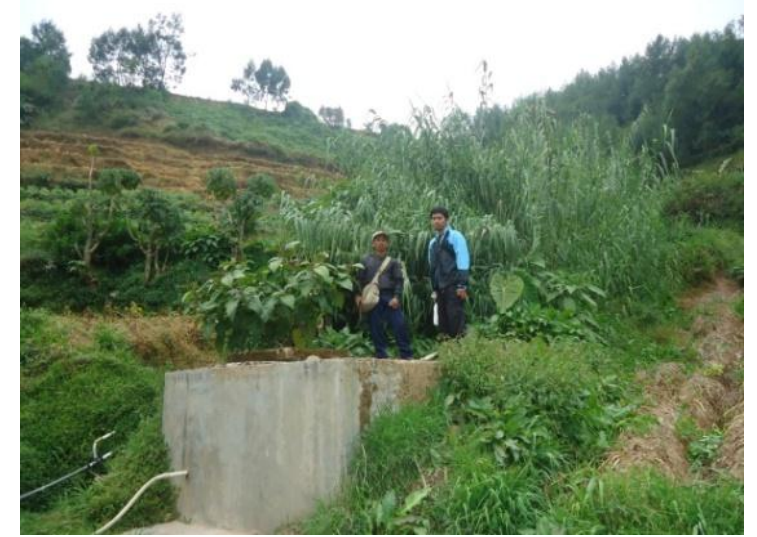

Bak pembagi utama yang berfungsi manampung air (Desa Sikunang bagian selatan, kamera menghadap selatan)
Sistem distribusi air di Desa Sikunang digunakan untuk membagi air berdasarkan volume yang ada agar tidak terjadi kesenjangan dalam pembagian air pada warga. Bak pembagi utama adalah bak yang paling besar diantara bak pembagi yang lain karena bak pembagi utama merupakan bak yang berfungsi menampung air langsung dari sumber mataair. Dari hasil penelitian yang dilakukan dapat diketahui pemanfaatan mataair yang ada di Desa Sikunang berdasarkan aspek teknik operasionalnya disajikan dalam Tabel 4.

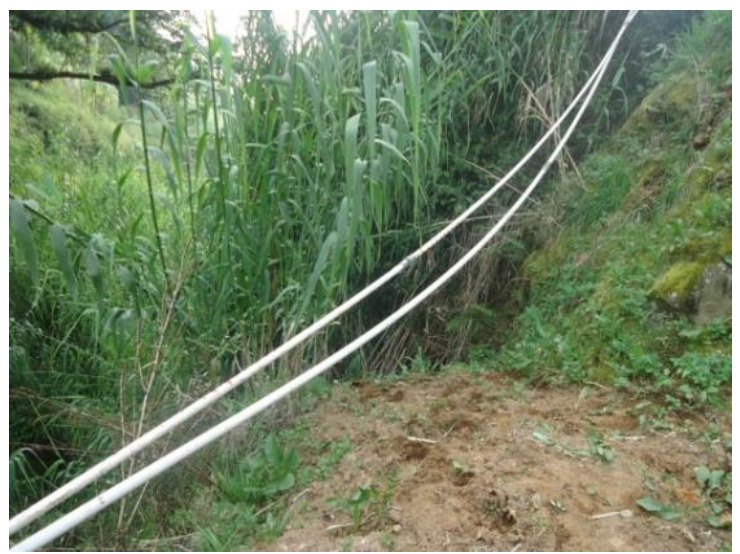

Pipa paralon yang berfungsi untuk mengalirkan air (Desa Sikunang bagian selatan, kamera menghadap utara)

Gambar 2. Teknik Operasional dalam Pengelolaan Mataair di Desa Sikunang

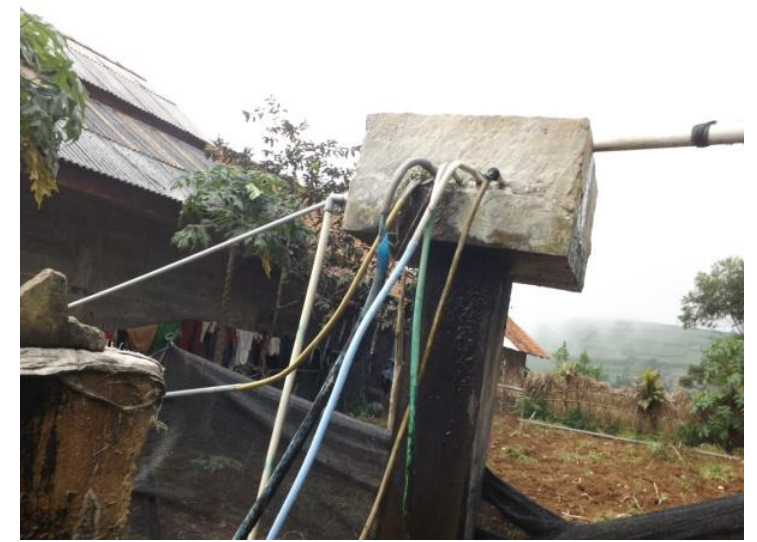

Bak pembagi desa yang berfungsi mambagi air kerumah warga (Desa Sikunang bagian utara, kamera menghadap timur)

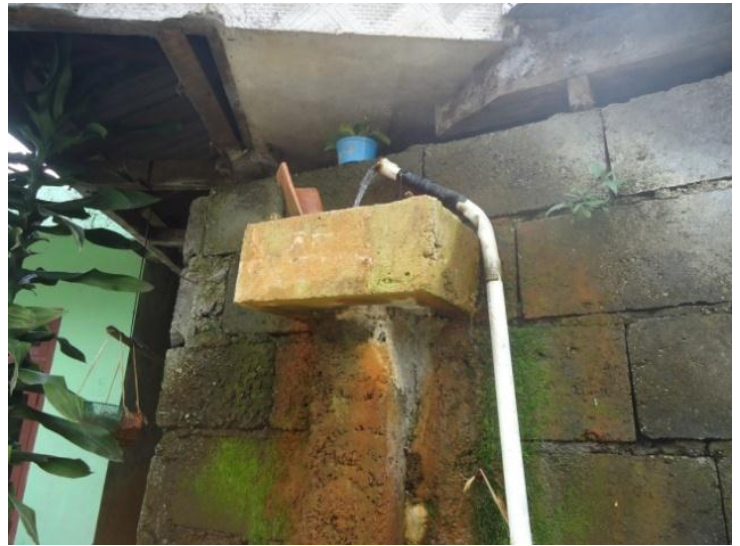

Bak berjalan yang berada di rumah warga (Desa Sikunang bagianutara, kamera menghadap timur)

Gambar 3. Bak Pembagi Desa dan Bak Berjalan 


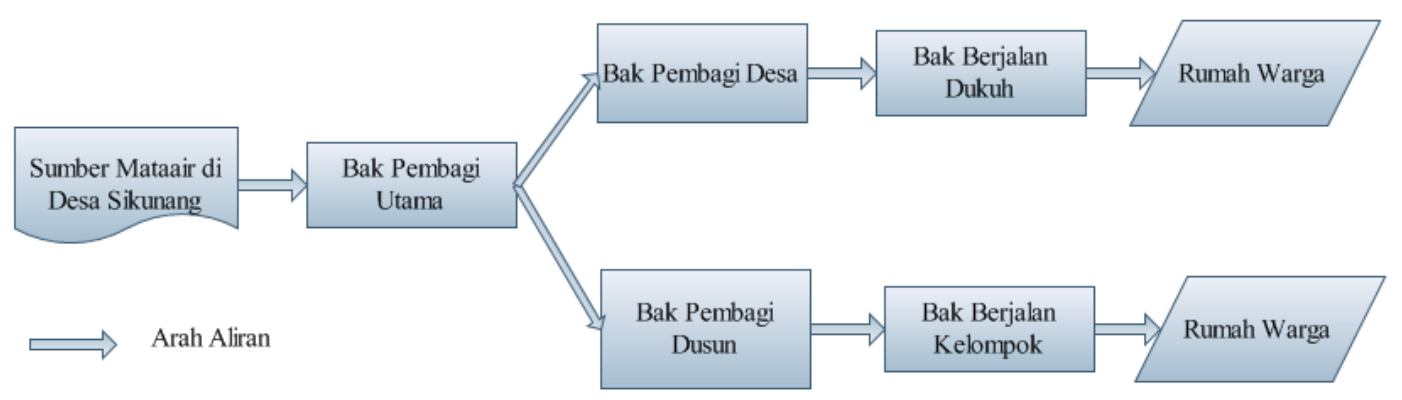

Gambar 4. Diagram Distribusi Mataair di Desa Sikunang

Aspek kelembagaan dalam pengelolaan mataair di Desa Sikunang merupakan bagian dari pengelolaan terkait dengan sumber daya manusia sebagai pengelola penyediaan air bersih. Berdasarkan hasil pengematan dan wawancara mengenai kelembagaan dalam pengelolaan mataair dapat diketahui bahwa pengelolaan mataair di Desa Sikunang belum mempunyai struktur kelembagaan yang memadai karena struktur kelembagaan yang ada masih sangat sederhana. Struktur kelembagaan yang sederhana membuat pengelolaan mataair masih sebatas tingkat kepercayaan dan kebersamaan warga. Kelembagaan dalam pengelolaan yang sederhanamembuat sistem monitoring dan evaluasi pengelolaan mataair tidak berjalan dengan baik hal ini dapat dilihat apabila terjadi kerusakan pada pipa maka perbaikan tidak dapat langsung dilakukan akan tetapi masih menunggu musyawarah untuk gotong royong memperbaiki kerusakan, hal ini akan mempengaruhi tersendatnya pasokan air bersih dari sumber mataair kerumah warga.

Dari hasil penelitian menunjukan bahwa pembiayaan dilakukan secara swadaya dan bantuan dari pemerintah untuk membangun sarana dan prasarana awal. Dari hasil wawancara yang dilakukan menunjukan bahwa pembiayaan yang dikeluarkan oleh warga untuk membangun sarana dan prasarana pengelolaan air berbeda dari jumlah nominalnya tergantung dari kesepakatan dan mataair yang digunakan oleh warga, biaya swadaya yang dikeluarkan warga berkisar antara Rp. 100.000 - Rp. 250. 000. Pembiayaan yang dilakukan setelah pengelolaan berjalan hanya pada saat terjadi kerusakan sarana dan prasarana yang berat dan harus mengeluarkan dana yang besar seperti kerusakan bak utama. Apabila kerusakan yang terjadi hanya memerlukan dana yang sedikit maka dana ditanggung warga dengan cara iuran sukarela.

Biaya iuran bulanan ditentukan berdasarkan musyawarah kelompok warga yang menggunakan mataair, besarnya iuran bulanan yang ditentukan berbeda-beda tergantung dari mataair yang dimanfaatkan warga. Biaya iuran bulanan yang dibebankan ke warga beragan antara Rp. 2000 - Rp. $6000 /$ bulan. Biaya iuran wajib yang dibayarkan warga tiap bulan bertujuan untuk dana operasional apabila terjadi kerusakan prasarana dan prasarana, serta sebagai dana perawatan rutin terhadap mataair agar kondisi lingkungan mataair tetap terawat dan terjaga.

Dari hasil pengamatan dan wawancara dengan tokoh masyarakat di Desa Sikunang untuk pengelolaan mataair yang ada belum terdapat peraturan formal yang tertulis dan bersifat mengikat. Dengan tidak adanya peraturan yang tertulis secara jelas menjadikan sering adanya pertemuan kelompok apabila terjadi kerusakan maupun perbaikan pada sarana dan prasarana pengelolaan air bersih di Desa Sikunang. Dengan peraturan yang tidak tertulis maka tidak ada mekanisme sanksi jika terjadi pelanggaran karena sistem peraturan mengenai pengelolaan air bersih lebih mengedepankan aspek sosial yang saling menghargai diantara warga.

Peran serta masyarakat Desa Sikunang dapat dilihat pada kegiatan gotong royong yang dilakukan warga dalam merawat sarana dan prasarana sumber daya air. Kegiatan gotong royong oleh masyarakat di Desa Sikunang dalam memperbaiki sumber air dilakukan setiap 3-4 bulan sekali, kegiatan gotong royong biasanya untuk membersihkan sumber mataair, sarana dan prasarana, serta sebagai sarana bersilaturahmi untuk membahas kegiatan yang akan dilakukan dalam pengelolaan mataair. Peran serta masyarakat lokal disajikan Tabel 5.

Pengelolaan sumber daya air bersih yang dilakukan oleh masyarakat lokal mempunyai latar belakang sejarah terkait dengan adat dan budaya masyarakat setempat agar sumber air tetap terjaga dan terawat. Mataair menjadi aspek yang sangat penting bagi masyarakat di Desa Sikuang dalam keyakinan dan berbudaya di masyarakat. Di Desa Sikunang keterkaitan antara budaya, alam, dan keterkaitan sosial menjadi aspek yang saling terintegrasi dari suatu fungsi sosial budaya masyarakat dalam mengelola dan memanfaatkan mataair yang ada di Desa Sikunang. 
Tabel 4. Sarana dan Prasarana Pengelolaan Mataair di Desa Sikunang

\begin{tabular}{clccc}
\hline No & Mataair & Tahun Awal Pengelolaan & Awal Pemanfaatan & Bak Pembagi \\
\hline 1 & Bengkok & 1984 & Irigasi & 2 \\
2 & Jurug Kulon 1 & 2012 & Pipa & 2 \\
3 & Jurug Kulon 2 & 2012 & pipa & 2 \\
4 & Jurug Tengah & 2011 & pipa & 2 \\
5 & Sigogor & 1994 & Irigasi & 3 \\
6 & Lempong & 1980 & manual & 2 \\
7 & Tlaga Sat & 2001 & Pipa & \\
8 & Lik-lik & 2001 & Pipa & 3 \\
9 & Senila & 2012 & Pipa & 1 \\
10 & Sidandang & Belum digunakan & - & \\
\hline
\end{tabular}

Sumber: Analisis Data Primer (2014)

Tabel 5. Peran Serta Masyarakat dalam Pengelolaan Mataair

\begin{tabular}{clcc}
\hline No & Mataair & Pertemuan warga & Gotong Royong \\
\hline 1 & Bengkok & 3 bulan sekali & 4 bulan sekali \\
2 & Jurug Kulon 1 & 3 bulan sekali & 3 bulan sekali \\
3 & Jurug Kulon 2 & 3 bulan sekali & 3 bulan sekali \\
4 & Jurug Tengah & 3 bulan sekali & 4 bulan sekali \\
5 & Sigogor & 3 bulan sekali & 3 bulan sekali \\
6 & Lempong & 4 bulan sekali & 3 bulan sekali \\
7 & Tlaga Sat & 3 bulan sekali & 3 bulan sekali \\
8 & Lik-lik & 4 bulan sekali & 4 bulan sekali \\
9 & Senila & 4 bulan sekali & 3 bulan sekali \\
10 & Sidandang & - & - \\
\hline
\end{tabular}

Sumber: Analisis Data Primer (2014)

\section{KESIMPULAN}

Kualitas mataair di Desa Sikunang masih berada pada kondisi yang normal dilihat dari sifat fisika, dan kimia, sedangkan kualitas mataair berdasarkan kondisi biologis berada pada kondisi yang kurang baik karena berada dibawah ambang batas aman. Tidak terjadi pencemaran pada mataair yang disebabkan karena pengoperasian PLTP yang berada di Desa Sikunang. Pengelolaan mataair di Desa Sikunang masih bersifat sangat sederhana dari segi sarana dan prasarana, kelembagaan, pembiayaan dan aspek peraturannya. Pengelolaan mataair di Desa Sikunang lebih mengedepankan fungsi sosial dari mataair dari pada fungsi ekonomi dan lingkungan. Pengelolaan mataair lebih mengutamakan fungsi sosial yang ada di Desa Sikunang antaralain kerja sama, saling menghormati, gotong royong, kebersamaan, serta mengedepankan kepentingan bersama dalam pengelolaan mataair.

\section{DAFTAR PUSTAKA}

Asdak, C. (2004). Hidrologi dan Pengelolaan Daerah Aliran Sungai. Yogyakarta: Gadjah Mada University Press.

Cahyono, Joko dan Karmono. (1978). Pengantar Penentuan Kualitas Air. Yogyakarta: Laboratorium Hidrologi UGM
Djiteng, M. (2005). Pembangkitan Energi Listrik. Jakarta: Penerbit Erlangga.

Effendi, H. (2003). Telaah Kualitas Air Bagi Pengelolaan Sumber Daya dan Lingkungan Perairan. Yogyakarta: Penerbit Kanisius.

Gupita, \& Sukanta Roy. (2007). Geotermal Energy and Alternative Resource For The $21^{S T}$ Century Amsterdam. The Netherlands.

Peraturan Menteri Lingkungan Hidup No. 08 Tahun 2009 Tentang Baku Mutu Kualitas Air Limbah Bagi Usaha dan atau Kegiatan Pembangkit Listrik Tenaga Termal.

Pikiran Rakyat. (2009). Ratusan Sumur di Dieng Beracun. Pikiran Rakyat. 01Juli 2009, Jawa Tengah.

PT. Geo Dipa Energi. (2006). Geological Map of Dieng Geothermal Field: Unpublished Report.

Sudarmadji. (2013). Mata Air Perspektif Hidrologis dan lingkungan. Yogyakarta: Sekolah Pascasarjana UGM.

Suprayogi, S., dan M.A. Marfai. (2005). Permasalahan Air dan Bencana Terkait Air Di Daerah Perkotaan. Prosiding Seminar Nasional Pengelolaan Sumber Daya Air, Antara Ketersediaan dan Konflik Kepentingan. 23-24 September 2005. Solo: Fakultas Geografi UMS.

Undang-undang No 27 Tahun 2003 Tentang Panas Bumi. 